\title{
Research on Hydroecology Management from the Perspective of Philosophy
}

\author{
Siliang Zhang ${ }^{1,3}$, Zhifeng Jia ${ }^{1,3, *}$, Zilong Guan ${ }^{1,3}$ andFeimin Zheng $^{2}$ \\ ${ }^{1}$ College of water resources and environment, Chang'an University, Shaanxi Xi'an \\ ${ }^{2}$ Institute of Water and Development, Chang'an University, Shaanxi Xi'an \\ ${ }^{3}$ Key Laboratory of Subsurface Hydrology and Ecological Effects in Arid Region, Ministry of Education, Chang'an University, Shaanxi \\ Xi'an
}

\begin{abstract}
To be nature-friendly is to do good to human beings themselves. Ultimately, the relation between human beings and water is being water-friendly. From the perspective of philosophy, this paper conducts indepth analysis and research on the Dujiang Weir Irrigation System, the typical case among water conservancy projects in ancient times, follows the philosophy and scientificity of Taiji Diagram in water control in ancient times, respects the rule of water itself and reduces the philosophy of Taiji Diagram into "one divides into two, unity of opposites, extremes meet, dynamic equilibrium". Meanwhile, it proposes that "those who are good at managing and utilizing water are kind to water". They are good at learning about water, comprehending water, mastering the essence of water, the features of water, the moving rule of water; good at utilizing water in a scientific way, control water in a unified way and taking water in a planned way; good at controlling water separately and utilizing water in a unified way; good at blocking water and releasing water; good at resisting water, diverting water and controlling water; good at protecting water, conserving water and maintaining water; good at coordinating the relation between human and water, integrating human and water and codeveloping human and water. With the intention of loving nature and water, people are kind to water, the source of life, from the philosophy of China's traditional science culture, in combination with modern water conservancy experience and methods. Human beings and water are symbiotic as people need to fight against flood and draught and strike a balance among the dependence on water, the utilization of water and the control of water. Those who are kind to water deem water as family members, friends and live by water, enjoy harmonious relation and integration with water and co-develop with water, thereby living long and prosper in an endless succession. In this way, human beings can better grasp the lifeline of ecology, improve ecological environment and achieve sustainable development.
\end{abstract}

\section{Foreword}

As the natural-occurring substance with the largest amount on the earth, water is one of the indispensable and the most important material resources on which human beings and other creatures survive and thrive [1]. With the society developing and human activities increasing, the ecological environment changes thereupon. The urbanization intensifies the conflict between human beings and nature, deteriorates the relation between human beings and water and causes floods in cities [2,3]. The way to handle the relation between human beings and water remains the urgent issue to be solved.

Xiaxiaozheng, the earliest book that records traditional farm work in China, takes astronomy, phenology, human and farm work into consideration as a whole[4].In the Spring and Autumn Period and the Warring States Period, the ideologies of all schools thrived,but the philosophy that went around most widely for the longest time was

*Corresponding author: 409538088@chd.edu.cn

1xaddzs10531@126.com, ${ }^{2}$ hydgeo_guan@163.com,

${ }^{3}$ zhengfeimin87@163.com "harmony between man and nature" and "the highest goodness is like water". Lao Zi also proposed that "Man follows the laws of the Earth, the Earth follows the laws of Heaven, Heaven follows the laws of Dao, and Dao follows the laws of Nature." From the existing literature today, Taiji was originally found in the Zhuangzi, "Dao was before the Taiji, and yet could not be considered high; It was below all space, and yet could not be considered deep. It was produced before heaven and earth, and yet could not be considered to have existed long; it was older than the highest antiquity, and yet could not be considered old." Later, it's found in the Companion to Changes, "In the system of Change there is the Great Ultimate. It generates the Two Modes (yin and yang). The Two Modes generate the Four Forms (major and minor yin and yang). The Four Forms generate the Eight Trigrams." The Book of Changes with abundant connotation, mentioned water control in many places, such as "nothing remains smooth without obstacles and nothing always moves forwards without moving backwards (the Book of Changes $\bullet$ the Tai 
Hexagram), "the danger is not so serious, the crisis is tided over"(the Book of Changes •the Kan Hexagram), etc. [5], which revealed that people have been studying the relation between man and water.

In recent years, many scholars have also carried out a series of studies on the relationship between man and water. In 1980, Qi Ping analyzed the construction of the Dujiang Weir Irrigation System and obtained the naive dialectics applied in water control of Li Bing and analyzed the dialectical relation between human and nature, water potential and terrain[6]. However, the article's attitude on water was still in the historical stage that man needed to conquer nature and was subject to limitations on the recognition on the relation between water and nature. In 2018, Shu Jiaqi also found dialectical unity in water control philosophy of the team of Li Bing [7]. The special study on the dialectics of water control carried out by the scholar, Li Guoying, is limited to the analysis of Li Bing's dialectical thoughts of water control[8], failing to have thorough research on its origin and cause. In the 17th Water Forum of China in 2019, in the report System Thinking and Practice of Green Development of WellCoordinated Environmental Conservation of the Yangtze River: Opportunities and Challenges, Academician Xia Jun also proposed that the hydroecology system building in the new era needs the inspiration of the classic water conservancy project of the Dujiang Weir Irrigation System on how to comply with and utilize the basic characteristics and rule of water. In 1973, Li Peicheng proposed "unified observation and management of three kinds of water bodies"[9] and comprehensively observed[10], treated and managed all water bodies in nature as a constantly transforming unity from the basic rules of water to manage space-time water control. Three kinds of water bodies include atmospheric water, surface water and underground water [11-12], which constitute a scientific and comprehensive system. The report of the Party Central Committee in 2017 took "adherence to the "harmonious co-existence between human and nature" as the fundamental strategy for sticking to and developing socialism with Chinese characteristics in the new era [13]. It also stated that human and nature are inseparable community and human needs to treat ecological environment as life, which is the solid interpretation of Marxist ecological thought at the present times. In April 2018, General Secretary Xi Jinping pointed out while surveying the Yangtze river basin: under the new situation, the key to promote the development of the Yangtze River Economic Zone is to correctly grasp the overall promotion and key breakthrough and coordinate ecological elements such as mountain, water, forest, field, lake, grassland from the integrality of ecosystem and systematicness of Yangtze river basin [14].

After studying the water control philosophy of $\mathrm{Li}$ Peicheng [15], the author conducts in-depth analysis and research on the Dujiang Weir Irrigation System, the typical case of ancient water conservancy project, follows the philosophy and scientificity of Taiji Diagram in water control in ancient times, respects the rule of water itself and generalizes the "those who are good at water control are kind to water" in light of "unified observation and management of three kinds of water bodies"[10].
Meanwhile, the author proposes to build a hydroecology system of macroscopic earth, thereby better grasping the lifeline of ecology, improving ecological environment and achieving sustainable development.

\section{Research Cases}

Located along the Minjiang River in the west of Chengdu, Sichuan (see figure 1), the Dujiang Weir Irrigation System was originally built in the last years of the reign of King Zhaoxiang of Qin(256 BC)[6] for the purpose of solving the flood of Chengdu Plain in Sichuan Basin with low elevation due to the river flow from the northwest with higher terrain to the southeast with lower terrain during the wet season of the Minjiang River, which greatly affected the production and life of common people. Therefore, during the service of Li Bing as the Governor of Shu Prefecture, the construction of the Dujiang Weir Irrigation System on the basis of Bie Ling's excavationwasorganized. During the engineering period, all kinds of difficulties of tremendous quantities, backward engineering equipment, and huge demand of labor were overcome and the construction was basically completed in $251 \mathrm{BC}$. The whole project consists of Fish Mouth(diversion embankment), Flying Sand Sluice(a sediment and overflow spillway), Lidui(a heap for irrigation guiding) [8], Baopingkou (a bottleneck-shaped irrigation gateway). As the earliest magnificent water conservancy project characterized by dam-free water diversion that has been in service until day in the world, it makes Chengdu Plain the land of abundance that ensures stable yields despite drought or excessive rain and covers vast expanse of fertile land. In 2000, it was confirmed as the world heritage in the 24th Session of World Heritage Committee, making it the only historic water conservancy project of China in the world heritage with outstanding universal values in both history and science.

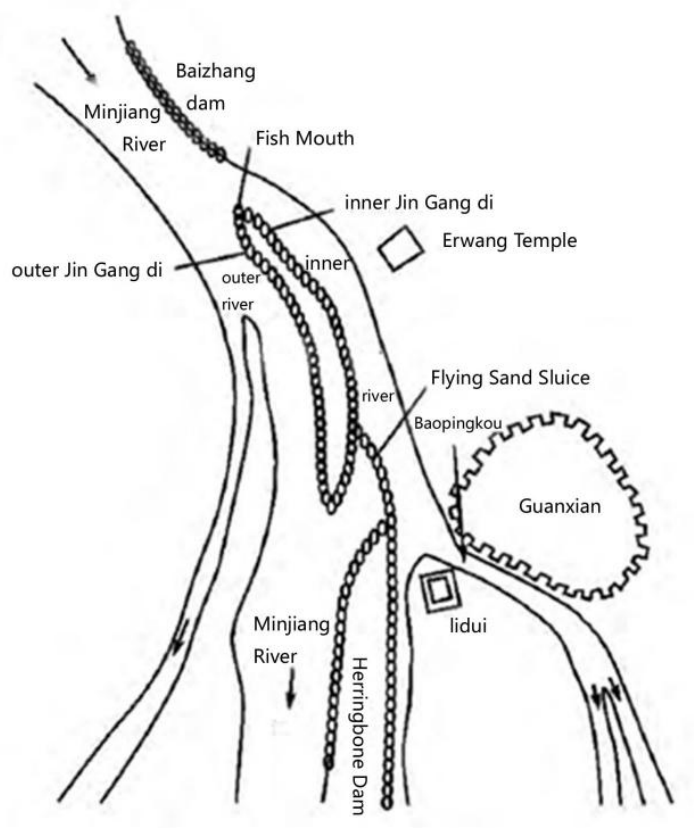

Fig1. Dujiang Weir planar graph. 


\section{Case Analysis}

In this paper, the philosophical nature of Taiji Bagua is summed up as "one divides into two, unity of opposites, extremes meet, dynamic equilibrium". Specific analysis as follows:

\subsection{One Divides into Two}

"Excavating Baopingkou and diverting floods for irrigation" marks the first step of the entire water control project of the Dujiang Weir Irrigation System. The project commenced from the excavation of Yulei Mountain and the water diversion to Chengdu. This is the first "one divides into two" of the Dujiang Weir Irrigation System with the purpose of dividing Minjiang river water for better control. This area was named "Baopingkou" due to its bottleneck shape. Baopingkou functions to adjust water amount of Minjiang River by determining the location of obstacles. Under the extreme harsh engineering conditions, Li Bing's team utilized the construction technique of "burning stone with fire" in an innovative way [8]. Based on poor thermal conductivity of stones, the rocks of Yulei Mountain were quickly poured with cool water after heating to cause rapid cooling of rock faces. As the rock was highly expanded inside, it cracked due to external shrinking and internal expansion, which greatly improved the efficiency of the excavation of Yulei Mountain. The stone heap separated was named "Lidui". This "one divides into two" reduced the flow of main channel, lightened the pressure during wet season of the river way on the west and lowered the chance of disaster. Meanwhile, it alleviated the drought in the east area.

"Dividing one river into two parts of forty percents and sixty percents". As the east part of Minjiang River features high terrain, it's hard for the river water to flow into Baopingkou. To solve this problem, the second "one divides into two" of the project was carried out: water diversion weir was built in the Minjiang River to divide the river water into two parts again: one part of river water flows to downstream and the other part flows into Baopingkou due to the centrifugal force generated by curve impact. The river in the west with large sectional area, shallow water level and higher river bed is called outer river; the river in the east with deep curve, smaller sectional area and lower river bed is called Inner River. During dry season when the river level is low, sixty percent of river water flows into Inner River with lower river bed and forty percent of river water flows along the outer river to downstream to ensure the basic production and living water demand of people living in Chengdu Plain with such water volume control [17]. When wet season approaches, due to the rise in water level, sixty percent of river water flows from outer river to downstream and forty percent of river water flows into Inner River. This design of "dividing two parts of forty percents and sixty percents" can adjust the inner and outer river amount dynamically in real time to protect people living by the river from the flood disaster and guarantee the water demand of people living downstream.

"Flying Sand Sluice divides the inner river". Baopingkou plays a role of flood diversion and disaster reduction. However, the water amount entering the irrigated area fluctuates as the water amount in flood season varies. To lower the fluctuation difference, this was the third "one divides into two" of Li Bing. "Flying Sand Sluice" spillway was added to the tail of Fish Mouth. The front end of water diversion weir was named "Fish Mouth" as it's shaped like fish head. The dams on both sides were called Jin Gang Di" with main body called "mighty weir" due to their strong water impact resistance. The curve built on spillway enables the flood that flows in to form ring current which will "fly" the mudstone carried by the flood out of the outer river when the water surface exceeds the top of weir so as to lower the sediment amount of inner river and Baopingkou, hence the name "Flying Sand Sluice"[18]. The height of weir top was designed based on water amount in the past years in a scientific way. When the river level of Inner River exceeded the weir top, the flood enters outer river over the weir top. At this time, the Fish Mouth has been submerged, which makes Lidui the second water diversion place to limit the maximum water mount entering Baopingkou and play a role of upper limit automatic regulating valve, which guarantees the water amount of the irrigation area and prevent the flood.

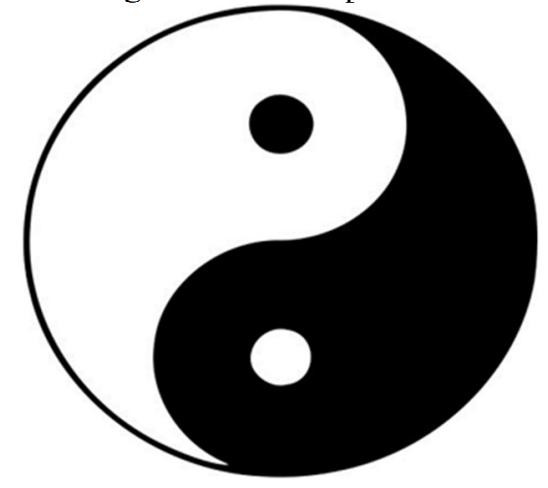

Fig2. Taiji Diagram

Li Bing's team applied the philosophy of "one divides into two" for three times in the project, which proves that it's never coincidental but the interpretation of his plain water control philosophy and the embodiment of Taiji Diagram (see figure 2) philosophical concept. The Taiji Diagram firstly shows a circle which represents the entire object. Secondly, there is separation of black and white parts, that is, "one divides into two". It divides one thing into two parts and breaks up the whole into parts. When solving problems, we should take them as a whole and "divide and rule" in light of actual situation to simplify problems. Meanwhile, while fully embodying dual character and symmetry of one thing, it contains the fundamental of Yin and Yang of Taiji. One divides into two is the scientific method that separates the entire problem and solve them. It features the process from entirety to locality, from one to two to divide and rule.

\subsection{Unity of Opposites}

The "in-depth dredging of sediments and control of the 
weir height to low level" in the water control of Li Bing's team reflects the unity of opposites of shallow and deep, high and low.

\subsection{1 "In-depth dredging of sediments"}

"in-depth dredging of sediments" is an important way for long-term maintenance of the Dujiang Weir Irrigation System. It's required to clean the sediments in the water channel at fixed time and amount. Li Bing's team put strict requirements on the depth of cleaning. For the water channel from Flying Sand Sluice to Lidui, if the cleaning goes too shallow, the throughput and sediments carried of the current cannot be guaranteed. In case the cleaning goes too deep, the water amount downstream will be increased. To keep water amount under reasonable condition, $\mathrm{Li}$ Bing's team took into consideration the measurement in the design and input stone horse in the water to make it the reference value of the depth of cleaning. If the cleaning exceeds the depth, the water flow rate will be enhanced, leading to flood downstream; if the cleaning fails to reach standard depth, the water flow rate is too low, failing to irrigate downstream. It shows unity of opposites of deep and shallow.

\subsection{2 "Control of the weir height to low level"}

It refers to the height control of Flying Sand Sluice, the height of which plays a crucial role in the entire Dujiang Weir Irrigation System. In usual water conservancy project, higher dam is usually built only to play a role of water retaining. However, Li Bing's team, through multiple measurements of wet season, dry season and daily water amount, obtained that the dam body needs to be lower than common dam while satisfying the functions of flood discharge and dam to make it a self-adjustable water conservancy project [19]. During wet season when the river water level rises to submerge the dam of Flying Sand Sluice, it can play the role of flood discharge and desilting. During dry season when the water level is lower than the Flying Sand Sluice, it plays the role of daily dam.

"Deep and shallow"and"high and low" both constitute two aspects of contradiction. Same as the Taiji Diagram, they are opposite to and interdependent with each other, presenting a dialectical relation of unity of opposites. The white area and black area of the Taiji Diagram are opposite to each other and constitute a whole part. It develops Eight Trigrams which includes Qian(三), Zhen(忈), Kan (三),

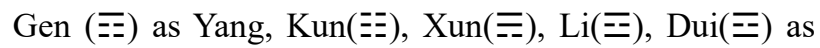
Yin. Each divinatory symbol has its mutually contradictory position. Qian(三) is opposite to Kun( $(\equiv)$, Zhen(云) is opposite to $\mathrm{Xun}(\bar{\Xi}), \mathrm{Kan}(\overline{\overline{-}})$ is opposite to $\operatorname{Li}(\equiv), \operatorname{Gen}(\bar{\Xi})$ is opposite to Dui(三). Opposite conflict embodies the absoluteness of contradiction of things. The absoluteness of contradiction and conflict of things is reflected in a "unified way" that white area and black area coexist in one Taiji. Eight divinatory symbols co-exist to form an integral whole, which shows unity of contradiction.

\subsection{Extremes Meet}

In the overall project of the Dujiang Weir Irrigation System, the design of Flying Sand Sluice is classic. Instead of piling soils or silts for construction, it puts cobbles into bamboo cages and piles them into the river one by one so as to fully satisfy the basic functions of weir for daily use [7]. In case of emergency of catastrophic flood that exceeds the load of weir body, the bamboo cages carrying cobbles will be brushed by the current with impact and scattered around to form self-inrush and allow river water to return to drag flow of the Minjiang River [20]. The water conservancy facility of Flying Sand Sluice completes the functions of weir and sluice at the same time. In the water control strategy of Li Bing's team, "replacing a dam with several weirs, allowing self-water control of high and low weirs, diverting water in wet season and combining water in dry season" reflects the process from quantitative change to qualitative change and countermeasures after change, which is identical with the change of the drop color in Taiji Diagram from black to white and from white to black. The design philosophy fully reflects the philosophy of "extremes meet" in Taiji Diagram. The Book of Changes . Feng stated that "every flow has its ebb" and the 55th chapter of Tao Te Ching of Lao $\mathrm{Zi}$ stated that "(For) things age after reaching their prime. That (violence) would be against the Tao. And he who is against the Tao perishes young." Sima Qian stated in his Records of the Grand Historian. Tianshu Ranked Biographies that "it's a common rule that every flow has its ebb". The aforesaid statements all expressed that "extreme meets" is a universal nature rule. Meanwhile, it's the objective rule for things development, which is clear in Taiji Diagram. There is one black point in the white area and one white point in the black area in Taiji Diagram. The white area develops from the smallest to the largest and reaches its utmost to show the black point. The black area reaches its utmost to show the white point. Meanwhile, symbols surrounding the Taiji Diagram are called "eight trigrams".

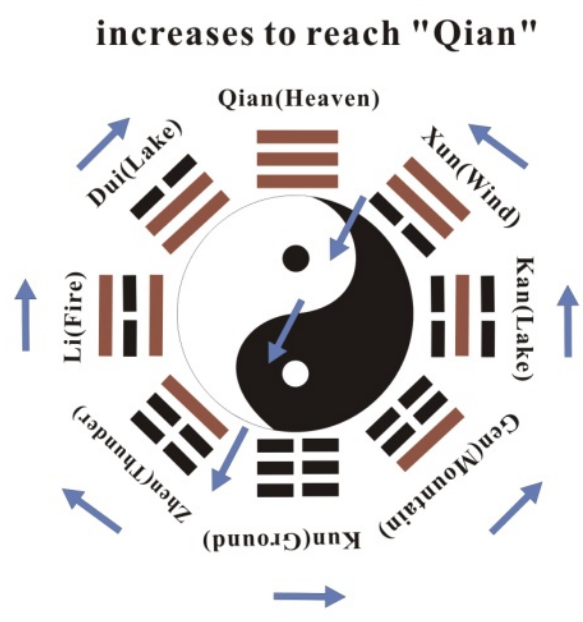

\section{Starting from "Kun"}

Fig3. Taiji Diagram Access Flow Trend

Among them, "_- is called "Yin hexagram", " _ " is called "Yang hexagram". From the figure, it can be seen 
that "the order from Kun (Ground) to Xun (Wind) via Gen (Mountain) and Kan (Water) is clockwise. Zhen (Thunder) reaches the opposite to Xun (Wind) along the curve in the Taiji. The order of Li (Fire) and Dui (Lake) to Qian (Heaven) is also clockwise (see Figure 3).

Starting from "Kun" that is most "Yin", "Yang" gradually increases to reach "Qian" that is most "Yang" and it's unfolded according to Kun, Gen, Kan, Xun, Zhen, Li, Dui, Qian as follows(see Figure 4):

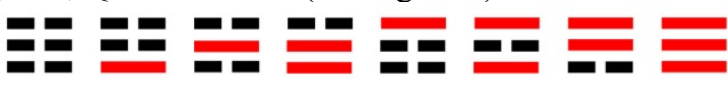

Fig4. Taiji Diagram breakdown drawing

The changes of red and black in the hexagram clearly indicate the rule of wane and wax and "extremes meet". "Extremes meet" is a dialectical view that things turn opposite under certain conditions, which is consistent with the dialectical negation in Marxist materialist dialectics. The dialectical negation means that things develop one process after another. The alteration of processes is achieved through negation. In the status of things development, two negations and three stages are experienced.That is affirmation, negation, negation negation, which shows a cycle. Therefore, the rule of negation- negation reveals the development trend of things.

\subsection{Dynamic Equilibrium}

Before building the Dujiang Weir Irrigation System, Li Bing's team had an all-round survey on surrounding terrain, water conservancy conditions, cultural situations of the Minjiang River, took the Fish Mouth, Flying Sand Sluice, Lidui, Baopingkou as a whole into consideration and followed the dynamic changes of water level, water amount, sediment deposition amount as well as water conservancy facilities. Firstly, in the Dujiang Weir Irrigation System, the "upper limit" of the water amount entering Baopingkou is determined by the set height of weir top to form the volitional check system composed of one-way threshold value. This was the earliest control theory in water conservancy project $[21,22]$. Secondly, to observe and control water amount of Inner River, in the absence of modern metric, Li Bing's team set three unified stone mark portrait as measurement standard and set upper and lower limit of water level of "exhaustion not to reach foot and overflow not to submerge shoulder". Presumably, the stone mark portrait is $200 \mathrm{~cm}$ in height with the distance from shoulder to foot of $150 \mathrm{~cm}-160 \mathrm{~cm}$. The precision for observing and controlling water amount reached centimeter, which totally satisfied the basic requirements of hydrologic monitoring. Meanwhile, Li Bing's team formulated annual repair system and corresponding standards: (1) it's required to repair and maintain engineering facilities at fixed time every year. (2) The engineering philosophy of "in-depth dredging of sediments and control of the weir height to low level". It's required to dredge silts at the bottom of river and build Flying Sand Sluice at a relatively low height. The dredging needs to reach certain depth to ensure water section and flow rate which are important basic data for modern water conservancy project. The flow formula in weir flow principle shows the functional relation between water section and flow rate. (3) The Dujiang Weir Irrigation System constitutes comprehensive "annual repair" system with "observation, measurement, control, regulation, repair, management" and continues to operate as a system. The establishment of the system shows the long-term view of Li Bing's team as constructors and reflects the comprehensive application of dynamic equilibrium characteristics of Taiji Diagram in practice. It marks that the Dujiang Weir Irrigation System becomes a complete water conservancy project system.

The "black point" and "white point" in the eight trigrams not only show the dialectical transformation view of "extreme meets", but also bear the two-way regulation mechanism of system. The so-called "wane and wax" promotes the steady progress of things in reciprocally determining and promoting contradiction. Positive feedback promotes things to develop and negative feedback constitutes self-discipline of things [23]. This feedback refers to forward extension and reverse selfdiscipline of system and constitutes "self-discipline extension" value system of Taiji Diagram. The ultimate expression of Taiji Diagram is equilibrium. The outer circle of Taiji means "static equilibrium" of the entire system for outside world. The black and white points inside of the circle mean "dynamic equilibrium" of the system. Stability is obtained in static equilibrium and development is obtained in dynamic equilibrium.

\section{Discussion}

As the most inseparable element in people's life on earth, water has a great influence on Chinese traditional culture with its biological ecological function, physical ecological function, chemical ecological function and landscape ecological function. In the primitive society and slave society period of China, the enlightenment triggered by water and water control practice formed by water control played an important role in the enlightenment and development of the culture, politics and economy of Chinese nation. As one of the classics in ancient China, the Taiji Diagram played adecisive role in the history of culture. However, people only recognized and understood Taiji Diagram from the perspective of Chinese culture and had fewer research on its formation roots and philosophy. The author held that its formation was rooted in the practice of ancient people to take surrounding natural things as research object to dig into its basic rule and summarize characteristics. Meanwhile, they summarized the application of water in water conservancy facilities as "one divides into two, unity of opposites, extremes meet, dynamic equilibrium". Among them, water, as the important natural element and production element, plays a vital role in Taiji Diagram and Chinese traditional culture. It can be said that water philosophy is the theoretical source of natural philosophy and cultural practices in Chinese traditional thought. The water drop shape evident in Taiji Diagram also shows that the natural element is important in the primitive philosophical system of Chinese civilization. The Book of Changes, Tao Te Ching and Xiaxiaozheng, all had dedicated research on the relation 
between water and nature, water and human.

People live by water to have sufficient drinking water, aquatic food. They pray for rain to guarantee harvest. None of the nations or countries can thrive without water. People view water differently as time changes [24]. The building of water conservancy facilities developed from the earliest "dam barrier" of Shun to "dredging" of Yu. The construction of the Dujiang Weir Irrigation System, the Lingqu Canal and the Grand Canal of Sui and Tang Dynasties all show changes in the view of people towards water and water control practical methods. In later industrial period when people pursued great development and lightened emphasis on water, the idealist idea that "man can conquer nature" came into being. The excessive utilization of water led to many problems relating to water, populations and society. Currently, people start to realize the importance of water. In the reports of the 19th National Congress of the Communist Party of China, General Secretary Xi Jinping pointed out that "human must respect nature, comply with nature and protect nature [25]. Only by following natural rules can human effectively prevent detours on the access to and utilization of nature [15]. In light of the philosophy of "unified observation and management of three kinds of water bodies" of academician Li Peicheng(see Figure 5), it's required to comprehensively observe, treat and manage all water bodies in nature as a constantly transforming unity from the basic rules of water to manage space-time water control. The author summarized that "those who are good at managing and utilizing water are the ones who are kind to water"[26,27]. They are good at learning about water, comprehending water, mastering the essence of water, the features of water, the moving rule of water; good at utilizing water in a scientific way, control water in a unified way and taking water in a planned way; good at controlling water separately and utilizing water in a unified way; good at blocking water and releasing water; good at resisting water, diverting water and controlling water; good at protecting water and maintaining water; good at coordinating the relation between human and water, integrating human and water and co-developing human and water. With the intention of loving nature and water, people are kind to the source of life- water from the philosophy of China's traditional science culture, in combination with modern water conservancy experience and methods. "Those who are good at managing and utilizing water are kind to water" is the inevitable trend for future water development.

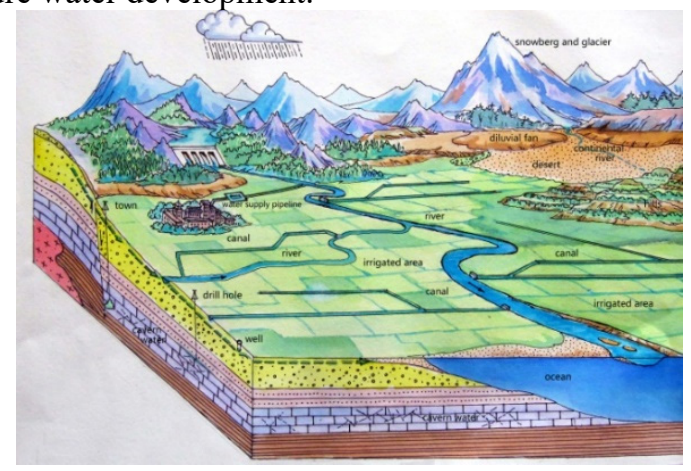

Fig5. Uniform Treat and Management of Three Kinds of Water [28].

\section{Conclusion}

Human history and water are closely connected. In this process, men's understanding of water also goes from shallow to deep, from phenomenal to intrinsic, and from partial to complete. Nowadays, people are starting to pay attention to the relationship between men and nature, and men and water, and the interaction and influence among them. The development of water science has also reached an unprecedented height, covering physics, chemistry, biology, engineering, ecology and other fields. The establishment of the in-depth scientific study of Dujiang Weir once again proved that the ancient Chinese classic Taiji Bagua is not only cultural, but also philosophical and scientific. This paper combines the principle of "one divides into two, unity of opposites, extremes meet, dynamic equilibrium" with the research results of modern hydroecology, and makes careful consideration from a macro perspective by taking into account the many factors affecting the water movement on Earth.

\section{Acknowledgments}

This work was supported by "111" Intellect Importation Project (B08039).

\section{References}

1. Li Peicheng.et al. (2019) Hydroecology.Science Press. BeiJing. p31.

2. Mohammad K H,Meng Qingmin.(2020)Athematic mapping method to assess and analyze potential urban hazard sand risks caused by flooding. Computers, Environment and Urban Systems.p 79-80.

3. Zhang Xuezhen.(2005)Study on city hydrology ecosystem system influence suffered from the urbanization and countermeasures-to take $\mathrm{Xi}$ ' an as an example. Chang'an University.

4. He Youqi.(1987)Content and era of Xiaxiaozheng.Journal of Northwest University Philosophy and Social Sciences Edition. (01) p 23-30.

5. Huang Shan.(2019) Analysis of Tianfu culture from water control of Li Bing.Sichuan Drama(06)p78-81.

6. Qi Ping,Li Shaoyu.(1980) The naive dialectics applied in water control of Li Bing.Social sciences (1)p 46-50.

7. Shu Jiaqi.(2018) Dialectical unity in water control philosophy of the team of Li Bing.Journal of North China Institute of Water Conservancy and Hydroelectric Power/Social Sciences Edition34 (1)p 16-18.

8. Li Guoying.(2001) Dialectics of water control .Water Resources in China.(4)p11-13.

9. Wang Jianying.(2016)Research on Theory and Practices of Uniform Treat and Management of Three Kinds of Water .Chang'an University. p 11-12.

10. Li Peicheng.(1999)On the Tri-state Balance.In:Management of Ecological Environment 
in the Loess Plateau of China--Proceedings of CCAST /World LaboratoryWorkshop.Xi'an.

11. Li Peicheng.(2014) It is the necessity of historical development in Harmonious Co-existence between Man and Nature.Science \& Technology Review.32(30)p 1.

12. Li Peicheng.(2013) Discussion on Harmonious Coexistence between Man and Nature, as well as Ecological Civilization Construction.Natural Resource Economics of China. 26(08)p5-9.

13. Li Tiezheng.(2017)The report of the 19th National Congress of the Communist Party of China is a milestone in the construction of ecological civilization.Http://www.qstheory.cn/wp/201710/24/c_1121850928.htm.

14. XI Jinping.(2018)Speech at further promote the development of regional integration in Yangtze River Delta.Http://jhsjk.people.cn/article/30056137.

15. Li Peicheng.(2000)Onthe New Thought Concerning Water related Human Activities.Engineering Science.p35.

16. Li Keke.(2020)Scientific principle and enlightenment of Dujiang Weir.Water Resources in China,.(03)p2832.

17. Zhang Shanghong.(2004)Study on Sustainable of Water Resources and Application of 3D Simulation in Dujiangyan.Tsinghua University.p43-46.

18. Wang Zhongjing,Zhang Teng.(2020)A preliminary discussion of the engineering ethics and advanced cultural in Dujiang Weir. Water Resources in China.(03)p 25-27.

19. Zheng Dajun,Wang Yancan,Zhou Ting.(2015)The Connotation and Enlightenmentof Water Culture of the Perspective of Water Ecological Civilization.Journal of Hohai University/Philosophy and Social Sciences.17(05) p 79-82.

20. Duan Gaiding.(2012)Architectural history of Dujiang Weir and Li Bing.Lantai World.(36)p117-118.

21. Makarieva A M and Cybernetics.(2008) Encyclopedia of Ecology.Second Edition Elsevier. p553-558.

22. Wan Baiwu.(2018)Development trend of cybernetics in the 21st century.Control Theory and Applications/To commemorate the 70 anniversary of the cybernetics since founding 1948-2018.35(01) p112 .

23. Li Yiyu.(1988)Positive feedback, negative feedback.Social Science Research.(3) p57-58.

24. Liu Guoping,Gong Jia.(2007)On interactive relationships between traditional philosophy and farmland irrigation in Pre-Qin Dynasty.Journal of Nanjing Agricultural University/Social Science. (3) p85-88.

25. Zhu Dangshenget al.(2020)Construction of ecofriendly water projects in the new age under the inspiration of Dujiang Weir. Water Resources in China. (03) p18-21.

26. Zhang Shuai.(2005) Water culture and sustainable development of Dujiang Weir.SichuanWater Resources.(01)p44-46.

27. Wang Guangqian,Zhong Deyu.(2020)Scientific principle and enlightenment of Dujiang Weir.Water Resources in China.(03)p10-12.

28. Li Peicheng. (2012). The Establishment and Historic Mission of Hydroecology.Journal of Irrigation and Drainage.(01),1-4. 